MATEC Web of Conferences 47, 00002 (2016)

DOI: $10.1051 /$ matecconf/20164700002

C) Owned by the authors, published by EDP Sciences, 2016

\title{
Keynote Abstract
}

\section{Keynote Speaker 1}

\section{Sustainability in Built Environment: Green Building Index (GBI) Platinum Certification UCTS Experience}

This keynote paper highlights the concept and objectives of green buildings. The fundamental features and characters of green buildings are presented. This paper focuses on the two primary issues; (i) the environmental protection and energy conservation and, (ii) the healthy indoor environment providing residential users with a comfortable and safe living.

The paper also highlights history of green building design with references to a number of green buildings in the world; their primary green features and rating agency.

The Malaysia Green Building Index (GBI), the Malaysia's green rating tools for buildings and complexes is presented in details taking the UCTS platinum rated GBI as an example. The scoring for each six key criteria of the GBI are presented and highlighted.

\section{Prof. Dato' Sabarudin Mohd \\ Peat Technology Research Center (PETRI) \\ University College of Technology Sarawak}

\section{Keynote Speaker 2}

\section{Sustainable Urban Stormwater Management - Key to Future Green-Blue, Resilience and Sustainability of Urban Environments}

Rapid urban growth in Malaysia over the last 30 years has resulted in increased stormwater flow into receiving waters, increased flood magnitude and frequency, and degraded water quality. Traditionally, stormwater management focuses on solving flooding through drainage of the urban areas to receiving water bodies. Presently, water supply should have not been an issue in Malaysia, considering the abundance of rainfall in this country. However, the reality is far from this. Malaysia ironically faces water stress in several heavily populated areas. Seasonal rainfall pattern, poor management and ineffectiveness of water supply system have led to occasional and seasonal water supply shortage in some states.

Based on these problems, Malaysian government has introduced a policy changing on Urban Stormwater Management Manual (MSMA). The introduction of Urban Stormwater Management Manual for Malaysia, or MSMA, changed the stormwater management landscape in the country. However, with the increasing demands for green technologies and addressing climate change, stormwater engineers are facing a stiffer challenge to produce effective and sustainable drainage 
system. This requires the need to inject new technologies or innovations into the design of drainage facilities.

The Sustainable Urban Stormwater System (SUDS) management solutions is consistent with objectives of stormwater management approach, i.e. control at source and stormwater treatment train which focus on both the quantity and quality control of urban runoff. The application of SUDS is a new development attempt to solve three major problems commonly encountered in Malaysia namely flash floods, river pollution and water scarcity during dry periods.

The success of the SUDS implementation proved that with innovation, managing stormwater in resilience and sustainability can be successfully managed without compromising on the overall project cost compared to traditional infrastructure system. A SUDS to the green-blue solutions not only has the potential to reduce the infrastructure costs, but it also reduces maintenance costs. It's also benefit the environment due to its minimise impact on local ecology, encourage the ecosystem values, function as well as preserved and providing benefits to the daily life's.

\author{
Prof. Nor Azazi Zakaria \\ River Engineering and Urban Drainage Research Centre (REDAC) \\ Universiti Sains Malaysia
}

\title{
Keynote Speaker 3
}

\section{Green Building Is Not Enough}

The definition of "sustainable development" considers three pillars: economic, social and environmental. To these are added the governance or institutional; and cultural pillars. The word 'green' is used to refer to the environmental dimension. In the construction industry, as indicated by the entrenched use of 'green', the approach has narrowly focused on the environmental considerations. This is reflected in the way the industry assesses the performance of buildings which are intended to deal with the negative impacts of buildings on sustainable development and to help to address the issues relating to sustainable development. This is an important subject as buildings are being seen as among major instruments for mitigating against climate change, and are therefore, main components of strategies for attaining national GHG emission-reduction commitments.

Various definitions of "Green Building", the drivers, obstacles and trends are considered. The question is asked: "Is green building the mainstream?" The focus is put on Malaysia and the drivers, key players, attainments and challenges of green building in the country are discussed. Areas which are not yet well covered are highlighted.

The definition of "sustainable development" is applied to formulate an appropriate definition for "sustainable building". Green building is then contrasted with sustainable building. It is shown that the former does not cover some major elements such as the social; economic (project, participants, district, national levels); and institutional and governance. It is suggested that such a broad definition is required in order that the right conceptualization is done, appropriate research is undertaken, suitable policies are formulated and the right inter-related actions are adopted, co-ordinated and integrated. The future of sustainable building in Malaysia is considered. The contributions to be made by these parties are highlighted: government, industry, clients, users and occupiers, and researchers.

\section{Prof. George Ofori}

School of Design and Environment

National University of Singapore 